OPEN ACCESS

Edited by:

Qingyi Zeng,

University of South China, China

Reviewed by:

Linsen Li,

Hebei University, China

Min Wang,

Jinan University, China

*Correspondence: Jibo Xiao

jbxiao@wzu.edu.cn

Zhida Huang

40098008@qq.com

Specialty section:

This article was submitted to

Inorganic Chemistry,

a section of the journal

Frontiers in Chemistry

Received: 07 January 2022

Accepted: 21 January 2022

Published: 08 March 2022

Citation:

Chen R, Pan Z, Chu S, Xiao J, Weng $R$

Ouyang $D$, Yang $Y$, Wu $X$ and Huang $Z$

(2022) Optimize the Preparation of

Novel Pyrite Tailings Based Non-

sintered Ceramsite by Plackett-

Burman Design Combined With

Response Surface Method for

Phosphorus Removal.

Front. Chem. 10:850171.

doi: 10.3389/fchem.2022.850171

\section{Optimize the Preparation of Novel Pyrite Tailings Based Non-sintered Ceramsite by Plackett-Burman Design Combined With Response Surface Method for Phosphorus Removal}

\author{
Ruihuan Chen ${ }^{1,2}$, Zhenlin Pan ${ }^{1}$, Shuyi Chu ${ }^{3}$, Jibo Xiao ${ }^{1 *}$, Rengui Weng ${ }^{4}$, Da Ouyang ${ }^{5}$, \\ Yunlong Yang ${ }^{1}$, Xiangting $\mathrm{Wu}^{1}$ and Zhida Huang ${ }^{6 *}$ \\ ${ }^{1}$ College of Life and Environmental Science, Wenzhou University, Wenzhou, China, ${ }^{2}$ Zhejiang Provincial Key Laboratory for Water \\ Environment and Marine Biological Resources Protection, Wenzhou University, Wenzhou, China, ${ }^{3}$ Wenzhou Academy of \\ Agricultural Sciences, Wenzhou, China, ${ }^{4}$ Indoor Environment Engineering Research Center of Fujian Province, Fujian University of \\ Technology, Fuzhou, China, ${ }^{5}$ Key Laboratory of Soil Contamination Bioremediation of Zhejiang Province, School of Environmental \\ and Resource Sciences, Zhejiang Agriculture and Forestry University, Hangzhou, China, ${ }^{6}$ Wenzhou Institute of Industry and \\ Science, Wenzhou, China
}

The large amount of untreated pyrite tailings has caused serious environmental problems, and the recycling of pyrite tailings is considered as an attractive strategy. Here, we reported a novel non-sintered ceramsite prepared with pyrite tailings (PTNC) as the main active raw material for phosphorus control, and the dosage effect of ingredients on total phosphorus (TP) removal ability was investigated. The results from Plackett-Burman Design (PBD) suggested the dosages of dehydrated sludge, sodium bicarbonate, and cement were the factors which significantly affect the TP removal ability. The Box-Behnken Design (BBD) based response surface methodology was further employed, and it indicated the interactions between different factors, and the optimized recipe for PTNC was $84.5 \mathrm{~g}$ (pyrite tailings), $10 \mathrm{~g}$ (cement), $1 \mathrm{~g}$ (calcined lime), $1 \mathrm{~g}$ (anhydrous gypsum), $3 \mathrm{~g}$ (dehydrated sludge), and $0.5 \mathrm{~g}$ (sodium bicarbonate). The optimized PTNC was characterized and which presented much higher specific area $\left(7.21 \mathrm{~m}^{2} / \mathrm{g}\right)$ than the standard limitation $\left(0.5 \mathrm{~m}^{2} / \mathrm{g}\right)$, as well as a lower wear rate $(2.08 \%)$ rather than $6 \%$. Additionally, the leaching metal concentrations of PTNC were far below the limitation of Chinese National Standard. The adsorption behavior of TP on PTNC was subsequently investigated with batch and dynamic experiments. It was found that the calculated max adsorption amount $\left(\mathrm{q}_{\max }\right)$ was about $7 \mathrm{mg} / \mathrm{g}$, and PTNC was able to offer a stable TP removal ability under different hydraulic retention time (HRT). The adsorption mechanism was discussed by model fitting analysis combined with XRD and SEM characterization, and cobalt phosphide sulfide was observed as the newly formed substance through the adsorption process, which suggested the existing of both physical and chemical adsorption effect. Our research not only offered an economic preparation method of ceramsite, but also broadened the recycling pathway of pyrite tailings.

Keywords: pyrite, solid waste recycling, unburned ceramsite, phosphorus removal, filter material, harmless treatment 


\section{INTRODUCTION}

Pyrite is the most abundant and widespread sulfide mineral which is mainly composed of iron and sulfur, and has been used as the raw material for sulfuric acid production for decades (Chandra and Gerson 2010). However, with the large-scale mining of pyrite, the pyrite tailings have caused serious environmental problems. As sulfide-rich waste materials, pyrite tailings can be oxidized in the presence of air and water (Garcia et al., 2005) spontaneously, which causes acid mine drainage (AMD) consequently (Malmström et al., 2006). AMD is considered as a serious and persistent environmental problem, which leads to the environment acidification and also releasing of significant amounts of various toxic metals into surface and groundwater (Heikkinen and Räisänen, 2009; Wang and Mulligan, 2009; Sahoo et al., 2013; Carvalho et al., 2014). Thus, the control of the pyrite tailings sourced pollution has become an important issue in the past decades, and various methods have been reported (Ouyang et al., 2015; Park et al., 2019; Dong et al., 2020a).

Remediation strategies are effective but unsustainable; thus, recycling of mine tailings is considered as a more economical way for reducing of tailings amount and limiting acid mine drainage formation. Currently, the most popular strategy for tailings recycling is replacing some portion of traditional but expensive construction materials, such as concrete admixture (Guo et al., 2016) and road construction admixture (Oluwasola et al., 2015). However, drawbacks still hindered the application of these strategies, such as higher energy consumption, dust generation increasing, and $\mathrm{CO}_{2}$ emission (Khale and Chaudhary, 2007), and novel effective and environment friendly method towards pyrite tailings recycling should be proposed. One important property of pyrite tailings should not be ignored, that is, large amounts of active reaction sites due to the existing of $\mathrm{Fe}$ and $\mathrm{S}$ in pyrite tailings, which can be used for removal of various pollutants (Yang et al., 2017). Thus, it is promising to use pyrite tailings as the active material to enhance the wastewater treatment process.

It is well known that the effluents of municipal wastewater treatment plants (WWTPs) contributed highly to these elements' concentrations in surface water, and the abundant nutrition elements (especially phosphorus) in water have caused a serious eutrophication problem in the past decades (Schindler et al., 2016). Thus the resource utilization and advanced treatment of waste water is a very meaningful way for the sustainable development of human beings, and strategies have been proposed (Bashar et al., 2018; Zeng et al., 2021). The biological aerated filter system (BAFS) has gained increasing attention due to smaller footprint and favorable ability for contaminants removal, which presented effective removal effect on COD, $\mathrm{NH}_{3}-\mathrm{N}$, and TN (Dong et al., 2020b). BAFS generally takes advantages of a granular media for the formation of microbial biofilms and provides the depth filtration action as well. Certainly, the biomass, bioactivity, and filtration action in BAFS is highly depending on the media character, and it also significantly determines the investment of construction and operating cost. Thus, research has reported focusing on the investigation of media performance of different materials in BAFS (Qiu et al., 2010; Bao et al., 2016; Bao et al., 2019), and ceramic particle was found as a favorable candidate due to its large specific surface area, high mechanical strength, and biological affinity (Yue et al., 2009; Han et al., 2013; Yang et al., 2015). However, the phosphorus removal by commercial ceramsites was unfavorable as yet (Jiang et al., 2014), and it is significant to propose strategies to improve its phosphorus removal.

Ceramsite was generally prepared with various active materials such as clay (Zhang et al., 2019), activated sludge (Nie et al., 2021) and fly ash (Mi et al., 2021) by high temperature calcination, which not only aim to improve the material properties and safety, but also promote the recovery and utilization of waste resource. However, the calcination is a high energy consumption process, and the crystal structure of raw material would be destroyed leading to the decrease of active adsorption sites. Consequently, non-sintered is considered as a more economic and effective way for preparation of ceramsites. Shao et al. (2019) prepared a non-sintered fly ash ceramsite for ammonia nitrogen adsorption, and which showed favorable adsorption capacity $(4.25 \mathrm{mg} / \mathrm{g})$ and standard-compliant leaching toxicity. Li et al. (2015) investigated the performance of non-sintered fly-ash ceramsite in the dual membrane processes for treatment of ethylene chemical plant wastewater, which indicated the biological aerated filter loaded with non-sintered ceramsite was a reasonable and effective method for pretreatment of reverse osmosis process. Besides fly-ash, the raw materials for non-sintered ceramsite preparation can be various, which provides more opportunities for recycling of solid wastes (He and Wang, 2019; Wang et al., 2021). Previous reports have already proved pyrite as a favorable absorbent candidate for wastewater treatment (Xu et al., 2006; Bulut et al., 2014; Ge et al., 2019; Chero-Osorio et al., 2021), and it is attractive to use pyrite tailings as the raw material for preparation of novel effective ceramsite towards phosphorus removal.

To our knowledge, there is no available report about the investigation of pyrite tailings based ceramsite as yet; thus, in this research, we employed pyrite tailings as the major active material aiming to prepare a novel non-sintered ceramsite (PTNC) for phosphorus control in wastewater treatment process. The main objectives are 1) investigate and optimize the recipe of raw materials mass ratio; 2) characterize the optimized PTNC with XRD, BET, SEM, and confirm its security by leaching toxicity metal concentration determination; and 3) investigate the application potential and clarify the removal mechanism of total phosphorus (TP) with batch adsorption experiment and dynamic column experiment.

\section{MATERIALS AND METHODS}

\subsection{Materials and Chemicals}

Pyrite tailings were collected from Anyang, Henan Province, and the chemical composition and XRD data of pyrite tailings are shown in Supplementary Table S1 and Supplementary Figure S1 respectively. The commercial $425^{\#}$ cement was used as 
adhesive and stabilizer, and calcium lime ( $\geq 60 \%$ effective calcium oxide) and anhydrous gypsum (industrial grade) were used as activator. Dehydrated sludge (Supplementary Table S2) is obtained from a sewage treatment plant in Wenzhou and used to reduce the product weight. Sodium bicarbonate (analytical grade) was selected as the pore-forming agent.

\subsection{Preparation of PTNC}

Firstly, $25 \mathrm{ml}$ deionized water was added into a mixture (totally $100 \mathrm{~g})$ containing pyrite tailings, cement, calcium lime, anhydrous gypsum, sodium bicarbonate, and dehydrated sludge with required mass ratio. After pelleting to spherical ceramsite $(6-10 \mathrm{~mm})$, it was air-dried for $12 \mathrm{~h}$ at room temperature, then the ceramsites were steam cured with an autoclave at $1.2 \mathrm{MPa}$ and $100^{\circ} \mathrm{C}$ for $10 \mathrm{~h}$. The final PTUC product was obtained by regularly curing with spraying water for 2 days.

\subsection{Optimization of the Components Dosage}

\subsubsection{Single Factor Experiment}

Single factor experiments were performed to preliminary define the dosage of raw materials, and the phosphate removal rate as well as porosity were selected as the indicators. For each single experiment, the total mixture weight was fixed as $100 \mathrm{~g}$, and the amount of pyrite tailings varied with the changing of corresponding ingredient amount. The test amounts of each material were shown as follows: cement $(10,20,30,40$, and $50 \mathrm{~g})$, calcium lime (1, 2, 3, 4, and $5 \mathrm{~g})$, anhydrous gypsum (1, 2, 3, 4 , and $5 \mathrm{~g})$, dehydrated sludge $(2,4,6,8$, and $10 \mathrm{~g})$, and sodium bicarbonate $(05,1,2,3,4$, and $5 \mathrm{~g})$.

\subsubsection{Plackett-Burman Experiments}

In order to obtain the significant influence factors on the phosphate removal capacity and porosity of PTNC, PBD method was used and the design scheme can be found in Supplementary Table S3, where five ingredients were coded respectively from code $\mathrm{A}$ to $\mathrm{E}$, phosphate removal capacity was set as $\mathrm{Y}$.

\subsubsection{Box-Behnken Design Based Response Surface Methodology}

Based on the significantly influence factors obtained from PBD experiments, the dosage of dehydrated sludge, sodium bicarbonate, and cement were selected and coded as $\mathrm{X}_{1}, \mathrm{X}_{2}$, and $\mathrm{X}_{3}$ respectively for Box-Behnken design to optimize the PTNC preparation process. Phosphate removal capacity (Y) was used as the indicators, and the design scheme is shown in Supplementary Table S4.

\subsection{Batch Adsorption Experiment for TP Removal}

A total of $4.5 \mathrm{~g}$ PTUC was weighted and added into the conical flask $(150 \mathrm{ml})$ and $50.0 \mathrm{ml}$ solution containing required concentration of potassium dihydrogen phosphate was added, and the vials were shaken at $100 \mathrm{rpm}$ for $5 \mathrm{~h}$ at $25^{\circ} \mathrm{C}$. The TP concentration in the filtered liquid was determined by $\mathrm{Mo}-\mathrm{Sb}$ anti-spectrophotometry method $(\lambda=700 \mathrm{~nm})$. The effect of $\mathrm{pH}$, PTNC dosage, co-existing anions, and temperature on adsorption were investigated respectively as well as the adsorption kinetic, and all the experiments were performed in triplicate vials. The removal rate of TP was calculated as follow equation:

$$
\text { TP removal rate }=\frac{c_{1}-c_{0}}{c_{0}} \times 100 \%
$$

where $c_{0}$ and $c_{1}$ were the initial TP and filtered TP concentration in aqueous respectively.

\subsection{Dynamic Adsorption of Total Phosphorus by PTNC in Column Experiment} In order to evaluate to the application potential of PTNC in TP control, an organic glass column $(50 \times 500 \mathrm{~mm})$ was used to perform the dynamic adsorption experiment. PTNC was prepared according to the optimized results and filled into the column to $400 \mathrm{~mm}$ height. Simulated wastewater containing $26 \mathrm{mg} / \mathrm{L} \mathrm{TP}$ was pumped into the column from the column bottom by a peristaltic pump, and the effect of hydraulic retention time (HRT) on TP removal was investigated in the range of $1-3 \mathrm{~h}$. The diagram of experimental device can be found in Supplementary Figure S2.

\subsection{Characterization of PTNC}

The physicochemical properties such as bulk density, apparent density, crush/wear rate, solubility in hydrochloric acid, voidage, and silt content were tested according to the Chinese standard (CJ/T 299-2008). Water absorption and cylinder compressive strength were tested as Chinese national standard (GB/T 17,431.2-2010). X-ray diffraction (XRD), BET method, and scanning electron microscopy (SEM) were employed to analyze the changes of crystal structure, specific surface area, and morphology after adsorption.

The leaching analysis of heavy metal was performed to evaluate the potential risk of PTNC. Briefly, sulfuric acid and nitric acid were mixed (mass ratio 2:1), and the added to deionized water and the $\mathrm{pH}$ was adjusted at 3.2. Then, $100 \mathrm{~g}$ PTNC was mixed with $1 \mathrm{~L}$ liquid above and shaken at $25^{\circ} \mathrm{C}$, $30 \mathrm{rpm}$, for $20 \mathrm{~h}$. After filtered with $0.45 \mu \mathrm{m}$ membrane, the concentration of heavy metals was determined by ICP-OES, and the results were compared with the limitation of the standard of Leaching Toxicity Identification of Hazardous Waste (GB5085.3-2007).

\section{RESULTS AND DISCUSSION}

\subsection{Single Factor Experiments}

Figure 1 showed the effect of five ingredients on the TP removal capacity of PTNC. In terms of cement, the TP removal rate decreased from 98.23 to $95.04 \%$ with the increasing of cement content from 10 to $50 \mathrm{~g}$ (Figure 1A). It can be found that the removal rate was stable in the dosage range of $10-30 \mathrm{~g}$, which can 

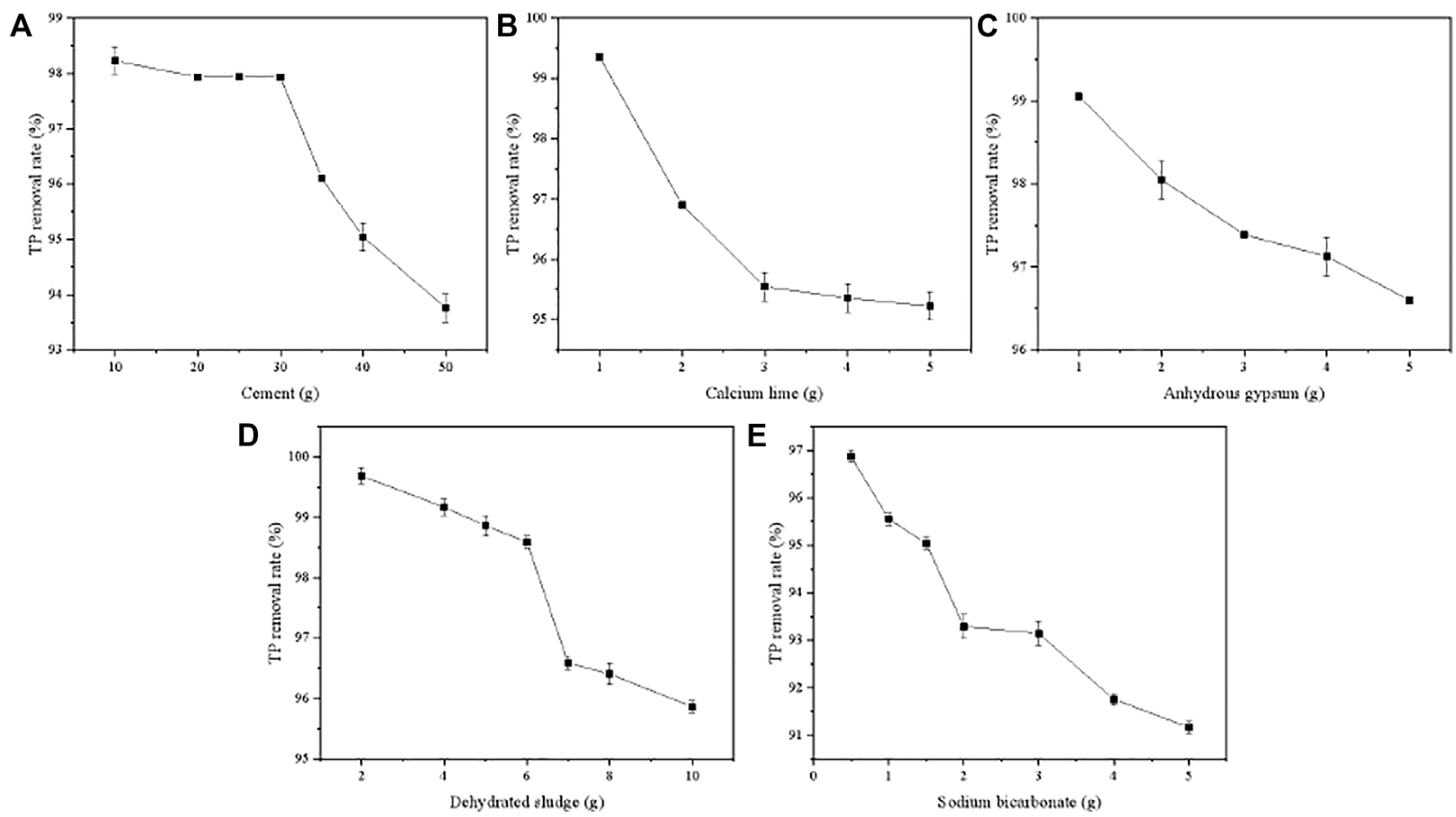

FIGURE 1 | Effect of ingredients on TP removal rate of PTNC.

attributed to the relative high amount of $\mathrm{Ca}$ (over 60\%) that react with $\mathrm{PO}_{4}{ }^{3-}$ to form a complex compound. As the dosage of cement was over $30 \mathrm{~g}$, the decreasing of removal rate can be ascribed to the lower porosity of PTNC, which was almost 0 as $50 \mathrm{~g}$ cement was added. The TP removal rate decreased from 99.35 to $95.23 \%$ with the increasing of calcium lime (Figure 1B). Adding of quicklime can increase the content of $\mathrm{Ca}$ in ceramsite to some extent, which is beneficial to the removal of TP. However, the excess using of quicklime will destroy the $\mathrm{Si}-\mathrm{O}$ bond in the product due to the alkaline environment, which leads to the reduction of the specific surface area. Therefore, the dosage of quicklime was selected as $1 \mathrm{~g}$. With the increasing of gypsum dosage from 1 to $5 \mathrm{~g}$, the TP removal rate decreased from 99.05 to $96.60 \%$ (Figure 1C). The main component of gypsum is $\mathrm{CaSO}_{4}$ which could increase the content of $\mathrm{Ca}$ in ceramsite, and was conducive to the removal of TP, but the excessive amount of gypsum leads to a longer digestion time of quicklime due to its high hygroscopicity, which reduces its activity and leads to a decrease in specific surface area and porosity. Therefore, the amount limitation of PTUC gypsum is set as $1 \mathrm{~g}$. In the terms of dehydrated sludge (Figure 1D), the TP removal rate showed decreasing tendency as the dosage increased. It can be ascribed to the high amount of organic matter that inhibited the hydration reaction and hindered the production of gelled substances, which resulted in a decrease in porosity (Figure 1E). A similar tendency can be found in the effect of sodium bicarbonate. Adding sodium bicarbonate can promote the forming of pores structures during steam curing, but too much sodium bicarbonate will release a large amount of $\mathrm{CO}_{2}$ at high temperature, which makes the skeleton structure become
TABLE 1 | Experimental design and response of Plackett-Burman experiment.

\begin{tabular}{llllllc}
\hline Runs & A & B & C & D & E & $\begin{array}{c}\text { Removal rate } \\
\text { (\%) }\end{array}$ \\
\hline 1 & & & & & & 56.77 \\
2 & +1 & +1 & -1 & +1 & +1 & 51.37 \\
3 & -1 & +1 & +1 & -1 & +1 & 92.84 \\
4 & +1 & -1 & +1 & +1 & -1 & 85.68 \\
5 & -1 & +1 & -1 & +1 & +1 & 52.83 \\
6 & -1 & -1 & +1 & -1 & +1 & 92.14 \\
7 & -1 & -1 & -1 & +1 & -1 & 49.71 \\
8 & +1 & -1 & -1 & -1 & +1 & 58.05 \\
9 & +1 & +1 & -1 & -1 & -1 & 56.86 \\
10 & +1 & +1 & +1 & -1 & -1 & 92.30 \\
11 & -1 & +1 & +1 & +1 & -1 & 68.05 \\
12 & +1 & -1 & +1 & +1 & +1 & 70.23
\end{tabular}

loose and difficult to form into pellets. Thus, the sodium bicarbonate dosage is set as $0.5 \mathrm{~g}$ here.

\subsection{Significant Factors Affecting the TP Removal Rate}

Based on the results of a signal factor experiment, a two-level PBD factorial design of 12 runs was employed to unbiasedly screen the variables that significantly affect the TP removal rate by PTNC (Table 1), and Figure 2 showed the analysis results. Five ingredients affected the TP removal rate as the following order: D (Dehydrated sludge) $>\mathrm{E}$ (Sodium bicarbonate) $>\mathrm{A}$ (Cement) $>\mathrm{B}$ (Calcium lime) $>\mathrm{C}$ (Anhydrous gypsum), and the dosage of dehydrated sludge affected TP removal rate 

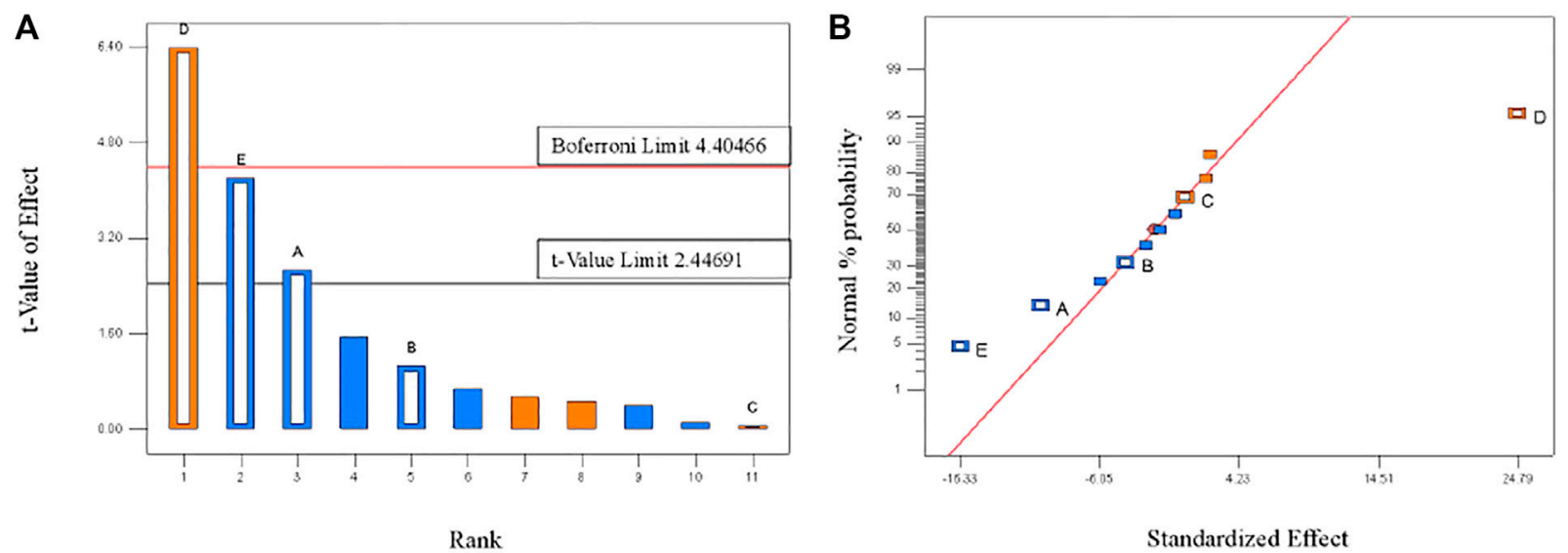

FIGURE 2 |Pareto plot (A) and normal distribution plot (B) of TP removal rates. The hollow square column represents the experimental data, and the solid square column represents the dummy error. The red line in Pareto plot indicates the 99\% confidence interval limitation and black line stands for 95\% confidence interval limitation.

TABLE 2 | Significant test for Plackett-Burman design regression model.

\begin{tabular}{ccccccc} 
& Factors & Adj SS & DF & Adj MS & F & p \\
\hline TP removal rate & Model & $3,018.45$ & 5 & 603.69 & 13.41 & 0.0033 \\
& A & 323.00 & 1 & 323.00 & 7.18 & 0.0366 \\
B & 51.07 & 1 & 51.07 & 1.13 & 0.3278 \\
C & 0.23 & 1 & 0.23 & 0.00518 & 0.9451 \\
D & 1843.70 & 1 & 1843.70 & 40.96 & 0.0007 \\
E & 800 & 1 & 800.44 & 17.78 & 0.0056 \\
& Error & 270.05 & 6 & 45.01 & - & - \\
& Total & $3,288.50$ & 11 & - & - & -
\end{tabular}

Adj SS, Adjusted Sum of Square; Adj MS, Adjusted Mean Square; DF, Degrees of Freedom, Wang et al., 2014).

most significantly which arrived at the $99 \%$ confidence interval. Sodium bicarbonate and cement also showed significant influence effect on TP removal rate, which were observed at 95\% confidence interval (Figure 2A). It can be also proved by the normal distribution plot (Figure 2B), where the points standing for dehydrated sludge, sodium bicarbonate, and cement showed significant dispersion from the fitted line. Table 2 shows the results of significant inspection of regression, which further proved the factors with significant effect on the TP removal rate were dehydrated sludge, sodium bicarbonate, and cement, and a model Equation 1 for TP removal rate (\%) (Y) was proposed; the $p$ value and $R^{2}$ for the model were 0.0366 and 0.9179 which indicated the validity of the model.

$$
\mathrm{Y}=68.91-5.19 \mathrm{~A}-2.06 \mathrm{~B}+0.14 \mathrm{C}+12.40 \mathrm{D}-8.17 \mathrm{E}
$$

\subsection{Box-Behnken Design for Preparation Optimization}

Based on the PBD results, the significant factors dehydrated sludge $\left(\mathrm{X}_{1}\right)$, sodium bicarbonate $\left(\mathrm{X}_{2}\right)$, and cement $\left(\mathrm{X}_{3}\right)$ were considered for further optimization using $\mathrm{BBD}$, and the matrix

\begin{tabular}{|c|c|c|c|c|}
\hline Run order & $\mathbf{X}_{1}$ & $\mathbf{X}_{2}$ & $\mathbf{X}_{3}$ & TP removal rate (\%) \\
\hline 1 & -1 & -1 & 0 & 60.45 \\
\hline 2 & 1 & $-1)$ & 0 & 89.69 \\
\hline 3 & -1 & +1 & 0 & 59.74 \\
\hline 4 & +1 & +1 & 0 & 81.03 \\
\hline 5 & -1 & 0 & -1 & 64.90 \\
\hline 6 & +1 & 0 & -1 & 92.00 \\
\hline 7 & -1 & 0 & +1 & 38.85 \\
\hline 8 & +1 & 0 & +1 & 78.92 \\
\hline 9 & 0 & -1 & -1 & 93.34 \\
\hline 10 & 0 & +1 & -1 & 80.88 \\
\hline 11 & 0 & -1 & +1 & 87.50 \\
\hline 12 & 0 & +1 & +1 & 81.47 \\
\hline 13 & 0 & 0 & 0 & 57.32 \\
\hline 14 & 0 & 0 & 0 & 60.15 \\
\hline 15 & 0 & 0 & 0 & 70.93 \\
\hline 16 & 0 & 0 & 0 & 69.66 \\
\hline 17 & 0 & 0 & 0 & 66.45 \\
\hline
\end{tabular}

for BBD along with the experimental results is shown in Table 3. By applying multiple regression analysis on the experimental data, the following second order polynomial model was obtained to describe the TP removal rate (2):

$$
\begin{aligned}
\mathrm{Y} & =+64.90+14.71 \mathrm{X}_{1}-3.48 \mathrm{X}_{2}-5.55 \mathrm{X}_{3}-1.99 \mathrm{X}_{1} \mathrm{X}_{2}+3.24 \mathrm{X}_{1} \mathrm{X}_{3} \\
& +1.61 \mathrm{X}_{3} \mathrm{X}_{2}-4.65 \mathrm{X}_{1}^{2}+12.48 \mathrm{X}_{2}^{2}+8.42 \mathrm{X}_{3}^{2}
\end{aligned}
$$

The adequacy of the model was checked using ANOVA and the results were shown in Table 4. The F value of model was 7.54 and the $p$ value (Prob $>\mathrm{F}$ ) was 0.018 , indicating that the model was highly significant, which was also confirmed by the nonsignificant $p$ value of "Lack of fit." It can be also found that the variable $\mathrm{X}_{1}$ as well as the quadratic terms $\mathrm{X}_{2}{ }^{2}$ and $\mathrm{X}_{3}{ }^{2}$ showed significant relationship with the TP removal rates. $R^{2}$ of the model was 0.9065 , suggesting the model has a good agreement for data 
TABLE 4 | ANNOVA for BBD.

\begin{tabular}{lccccc}
\hline Source & Adj SS & DF & Adj MS & F-value & p-value \\
\hline Model & $3,197.96$ & 9 & 355.32 & 7.54 & 0.0072 \\
$X_{1}$ & 1731.58 & 1 & 1731.58 & 36.75 & 0.0005 \\
$X_{2}$ & 97.01 & 1 & 97.01 & 2.06 & 0.1945 \\
$X_{3}$ & 246.29 & 1 & 246.29 & 5.23 & 0.0561 \\
$X_{1} X_{2}$ & 15.80 & 1 & 15.80 & 0.34 & 0.5806 \\
$X_{1} X_{3}$ & 42.03 & 1 & 42.03 & 0.89 & 0.3764 \\
$X_{2} X_{3}$ & 10.31 & 1 & 10.31 & 0.22 & 0.6541 \\
$X_{1}{ }^{2}$ & 91.11 & 1 & 91.11 & 1.93 & 0.2070 \\
$X_{2}{ }^{2}$ & 655.62 & 1 & 655.62 & 13.91 & 0.0074 \\
$X_{3}{ }^{2}$ & 298.33 & 1 & 298.33 & 6.33 & 0.0400 \\
Error & 329.85 & 7 & 47.12 & - & - \\
Lack of fit & 188.36 & 3 & 62.78 & 1.78 & 0.2908 \\
Pure error & 141.48 & 4 & 35.37 & - & - \\
Total & $3,527.81$ & 16 & - & - & -
\end{tabular}

Adj SS, Adjusted Sum of Square; Adj MS, Adjusted Mean Square; DF, Degrees of Freedom, (Wang et al., 2014).

Coefficient of variation - 9.46\%; Signal to noise ratio - 9.738; $R^{2}-0.9065 ; R_{A d j}^{2}-0.7863$.

fitting. The ratio of signal to noise (Adeq Precision) was 9.738 which was over 4 , and the coefficient of variation (C.V.) was lower than $10 \%$, indicating the reproducibility of the model. These statistical analysis results showed that the model was reliable and accurate, and can be used for the analysis and prediction of TP removal by PTNC. The statistical model was further validated by experiments with PTNC prepared under different conditions (Supplementary Figure S3). It can be said that the predicted model response for experimental value was close to the predicted value, thus validating the model.

The optimum level of each variable and the effect of their interaction on TP removal rate were investigated by constructing response surface plots and their corresponding contour plots (Figure 3). With the increasing of dehydrated sludge dosage, the TP removal rate of PTUC showed an increasing trend. The response surface showed a steep slope (Figure 3A), which indicated the interaction between factors. The increasing of dehydrated sludge content increased the active adsorption sites for phosphate combination, which improved the TP removal rate reasonably. When the dehydrated sludge content was fixed as $4 \mathrm{~g}$, the TP removal rate of PTUC showed non-significant change with the increment of cement dosage, which was about $80 \%$ (Figure 3B). It was reported that the phosphate anion will react with $\mathrm{Ca}^{2+}$ and $\mathrm{OH}^{-}$which formed complex precipitates (Qiu et al., 2015). The addition of cement increased the $\mathrm{Ca}$ amount in PTNC; however, the increasing of cement dosage would decrease the porosity which hindered mass diffusion, which can be further proved by the high interaction caused by the pore forming substance sodium bicarbonate (Figures 3A,C).

In order to deter the optimum preparation conditions, the primary target value was obtained by calculating the model, and the raw materials dosage was rounded and fitted again with the model for optimal target value. PTNC was prepared consequently, and TP removal rate was tested to calculate the error and determine the fitting result (Table 5). The errors between the measured values of TP removal rate and the predicted values of the model fitting were $1.80 \%$, indicating that the fitting effect was favorable and the model was reliable. Thus the optimal raw material ratio (per $100 \mathrm{~g}$ ) was $84.5 \mathrm{~g}$ (pyrite tailings), $10 \mathrm{~g}$ (cement), $1 \mathrm{~g}$ (calcined lime), $1 \mathrm{~g}$ (Anhydrous gypsum), $3 \mathrm{~g}$ (dehydrated sludge), and $0.5 \mathrm{~g}$ (sodium bicarbonate).

\subsection{Characterization of PTNC Prepared Under Optimized Condition}

The surface of PTUC is rough, with low smoothness, dark gray color, and pore structure on the outer surface (Figure 4A), and the apparent morphology observed by SEM showed many grooves on its surface, with uneven interior and abundant pores, indicating its large specific surface area. The determined specific surface area and pore size was consistent with the above conclusion (Supplementary Table S5). It can be said that PTNC was suitable for the attachment and growth of microorganisms. The physical parameters of PTNC meet the requirements of relevant standards favorably (Supplementary Table S6). The high apparent density and water absorption rate ensures the adsorption characteristics of PTNC. And the favorable mechanic strength such as low wear rate and higher cylinder compressive strength ensured the application possibility of PTNC, and the porous nature is a benefit for the attachment of functional microbial community. XRD analysis confirmed the PTNC is mainly composed of $\mathrm{FeS}_{2}, \mathrm{CaSO}_{4}$, and $\mathrm{SiO}_{2}$ (Supplementary Figure S4). The peak strength of $\mathrm{CaSO}_{4}$ crystal is the most obvious, followed by $\mathrm{SiO}_{2}$, indicating the formation of $\mathrm{SiO}_{2}$ during the steam curing process of PTNC, acting as the framework structure of PTNC, which was also consistent with the low wear rate observed. Moreover, the heavy metal ion concentration in the PTNC leachate is much lower than the limitation of Hazardous Waste Identification Standard Leaching Toxicity Identification (GB5085.3-2007) (Supplementary Table S7), which indicate its security to the environment.

\subsection{The Adsorption Behavior and Mechanism of TP on PTNC}

Simulated wastewater containing $25 \mathrm{mg} / \mathrm{L}$ TP was employed to investigate the adsorption kinetic. The adsorption amount showed increased tendency with the increasing of reaction time (Figure 5A). The adsorption equilibrium was observed at $16 \mathrm{~h}$, where the TP concentration decreased to $0.43 \mathrm{mg} / \mathrm{L}$, meeting the V level of "Surface water Environmental Quality Standard" (GB 3838-2002), and the equilibrium adsorption capacity was $0.2864 \mathrm{mg} / \mathrm{g}$. As the mostly using models for description of adsorption kinetic, pseudo first-order and pseudo second-order models (Text S1) were used to fit the experimental data (Supplementary Table S8) (Chen et al., 2019). Although the correlation coefficients of both two kinetic models were similar $(>0.9)$, the predicted adsorption capacity with pseudo first order model is $0.2995 \mathrm{mg} / \mathrm{g}$ which is close to the experimental value $(0.2864 \mathrm{mg} / \mathrm{g})$. Therefore, the pseudo first-order kinetic model can describe the TP adsorption process on PTNC better. The both two well fitted models indicated that both of chemisorption and physisorptions 

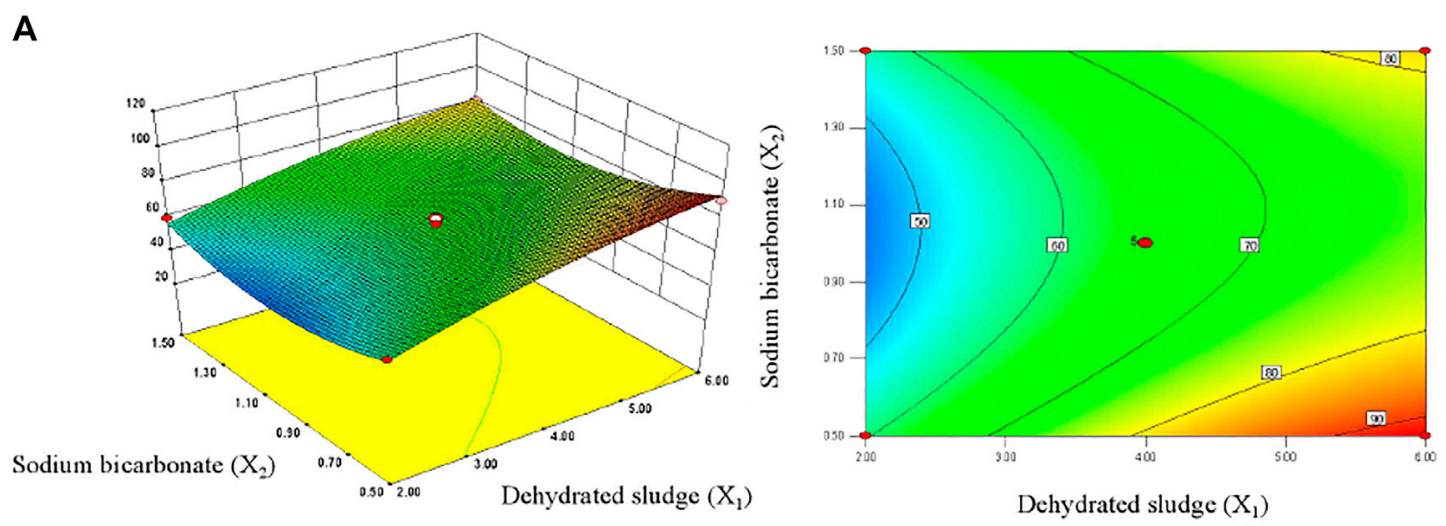

B
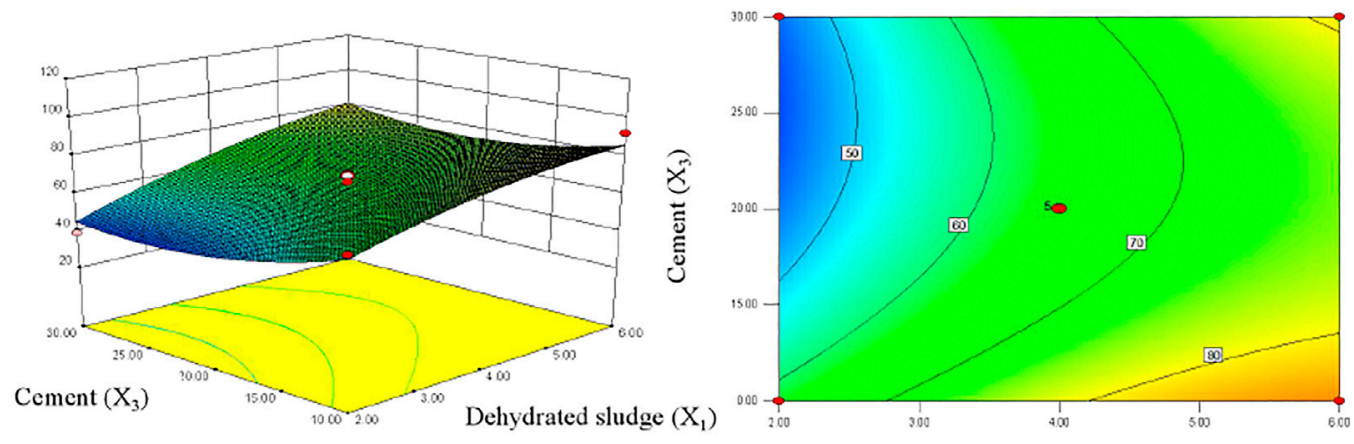

C
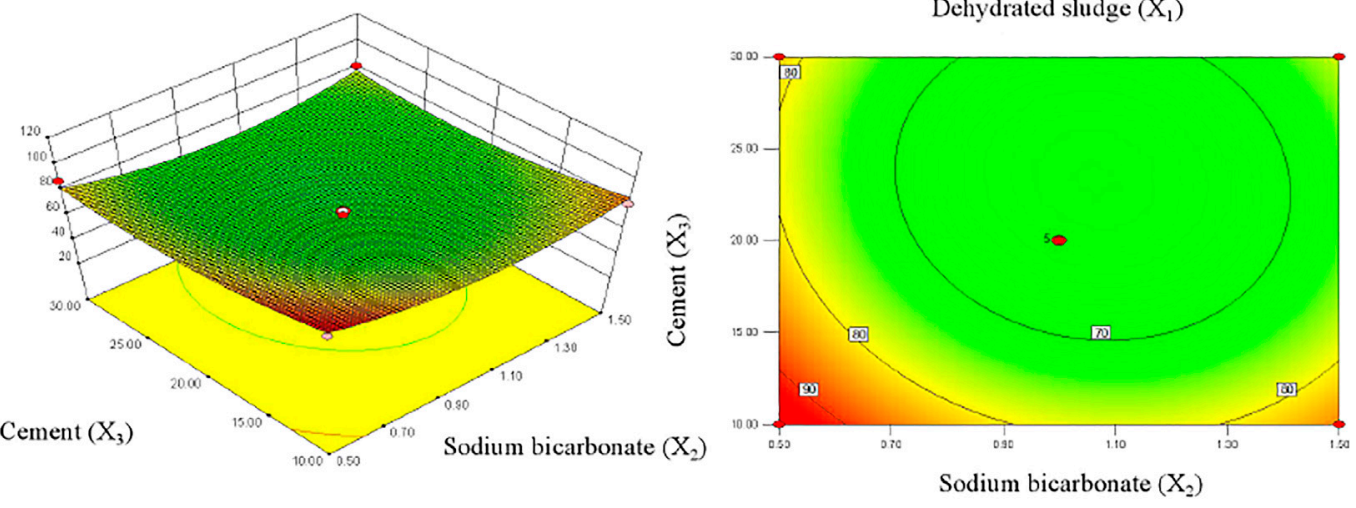

FIGURE 3| Surface and contour plot showing interactions between variables on TP removal rates by PTNC. (A) stands for interaction between dehydrated sludge and sodium bicarbonate; (B) shows interaction between dehydrated sludge and cement; (C) stands for interaction between sodium bicarbonate and cement.

TABLE $\mathbf{5}$ | The optimization results of regression.

\begin{tabular}{lccccc}
\hline & $\mathbf{X}_{\mathbf{1}}$ & $\mathbf{X}_{\mathbf{2}}$ & $\mathbf{X}_{\mathbf{1}}$ & $\begin{array}{c}\text { TP removal } \\
\text { rate (\%) }\end{array}$ & $\begin{array}{c}\text { Degree of } \\
\text { fitting }\end{array}$ \\
\hline Primary & 3.1 & 0.5 & 10 & 89.41 & 96.3 \\
Optimal & 3 & 0.5 & 10 & 88.55 & 95.5 \\
Actual & 3 & 0.5 & 10 & 86.96 & - \\
Error & - & - & - & $1.80 \%$ & - \\
\hline
\end{tabular}

existed in the process of TP removal by PTNC, which were mainly ion exchange effect and precipitation probably (Yang et al., 2017). Generally, adsorption process can be divided into several steps, firstly the adsorbate in aqueous diffuses from aqueous to the adsorbent surface, then the surface loaded adsorbate diffuses to internal pores (diffusion within particles), and finally the internal adsorption sites are saturated. It can be found that the adsorption rate decreased apparently from 4 to 10 $\mathrm{h}$, which can be attributed to the chemisorption of TP by PTNC leading to the formation of cobalt phosphide sulfide (Supplementary Figure S4) and decreased of the pore size of PTNC (Supplementary Table S5), thus the diffusion of phosphorus to the internal pores can be hindered.

The adsorption thermodynamics was investigated through three isotherms at different temperatures (Figure 5B), through the data fitting with Langmuir and Freundlich isotherm models (Text S2) (Chen et al., 2019). It can be found that Langmuir model fitted better with the isotherms, and indicated the mono- 


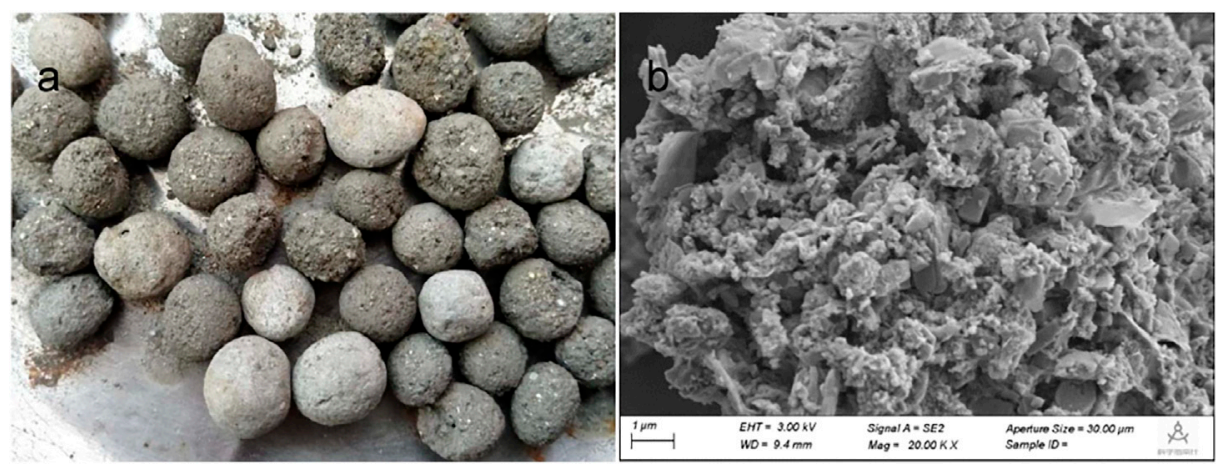

FIGURE 4 | The appearance of PTNC (6-8 mm diameter) (A) and SEM images of PTNC (B)
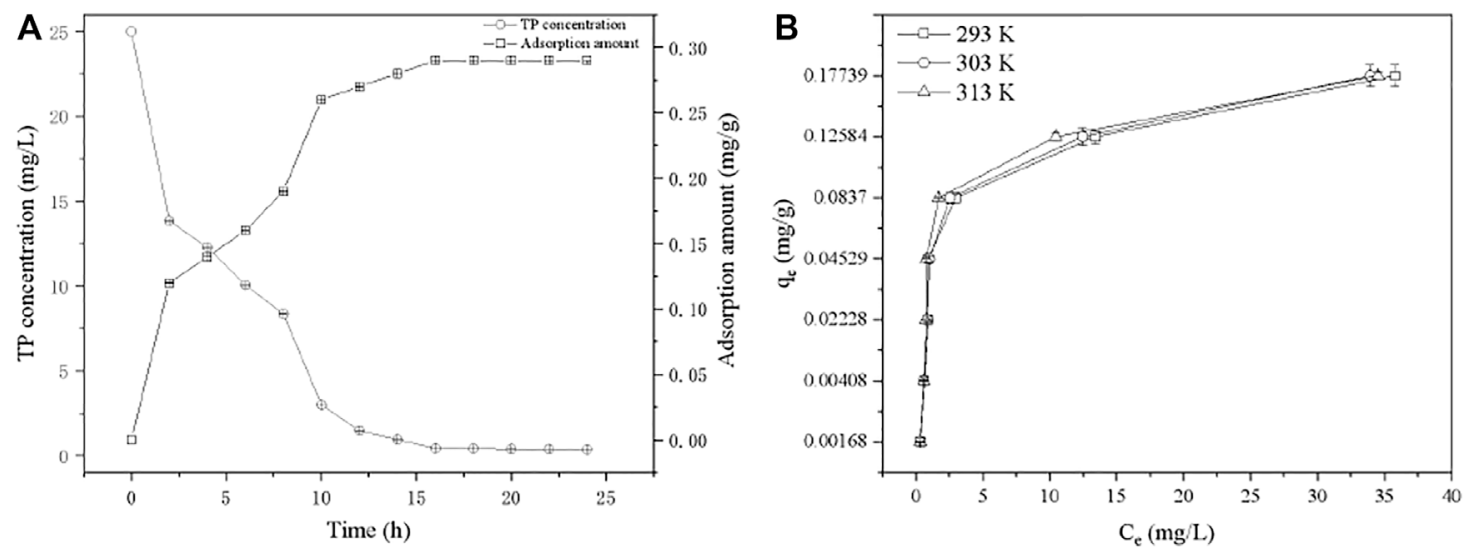

FIGURE 5 | Kinetic curve (A) and isotherms (B) of TP adsorption by PTNC.

layer adsorption process (Supplementary Table S9). The thermodynamic parameters were calculated (Text S3), and the negative $\Delta \mathrm{G}$ suggested the TP removal is a spontaneous process (Supplementary Table S10). Additionally, the obtained negative value of $\Delta \mathrm{H}(-11.69 \mathrm{~kJ} / \mathrm{mol})$ and positive value of $\Delta \mathrm{S}(153.09 \mathrm{~J} /$ $\mathrm{mol} / \mathrm{K})$ together indicate that the adsorption is an exothermic reaction and is both enthalpy and entropy driven. Generally, the adsorption process is an entropy reduction process; however, there are existing adsorption cases that presented entropy-positive with a negative enthalpy change (Wen et al., 2010). For TP removal process by PTNC, it can be ascribed to the releasing of $\mathrm{Fe}^{3+}, \mathrm{Ca}^{2+}$, and $\mathrm{OH}^{-}$from PTNC surface which increased the entropy. And these ions would react with phosphate and formed of precipitation on the surface of PTNC which additionally make contribution to the entropy increasing. It can be found that the specific surface of PTNC increased obviously after adsorption (Supplementary Table S5). Moreover, the XRD analysis of the PTNC after adsorption (Supplementary Figure S4), which suggested the newly formation of cobalt phosphide sulfide, and the SEM

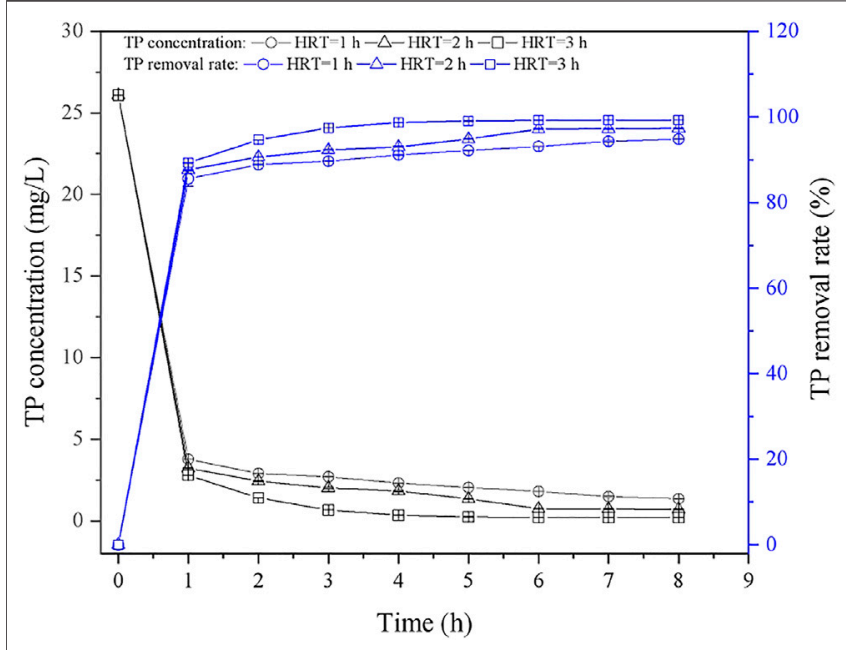

FIGURE 6 | Dynamic adsorption curves of TP removal by PTNC under different HRT. 
TABLE 6 | Comparison of the TP removal ability of different ceramsites.

\begin{tabular}{|c|c|c|c|c|}
\hline Ceramsite & Calcining temperature $\left({ }^{\circ} \mathrm{C}\right)$ & $\begin{array}{l}\text { Initial TP concentration } \\
\text { (mg/L }\end{array}$ & Adsorption capacity (mg/g) & Reference \\
\hline CFAWS/OS-op & 1,050 & 100 & 4.51 (calculated) & Cheng et al. (2018) \\
\hline Slag ceramsite & 1,000 & 10 & 10.5 & Liu et al. (2021) \\
\hline N\&P-adsorbed ceramsite & 800 & 100 & 0.93 & Shao et al. (2022) \\
\hline DWTS ceramsite & 1,050 & 20 & 1.43 & Chen et al. (2019b) \\
\hline PTNC & Non & 25 & 6.9978 & This work \\
\hline
\end{tabular}

morphology observation (Supplementary Figure S5) of the PTNC after adsorption further confirmed the precipitation formation during the adsorption process. It is consistent with the previous report (Ge et al., 2019).

Figure 6 showed the dynamic TP removal curves under different HRT $(1,2,3 \mathrm{~h})$. In the initial stage, the TP concentration in effluent decreased rapidly, which is ascribed to the large amount of active adsorption sites in the initial stage (Chu et al., 2014). The TP concentration tended to be stable after running for $8 \mathrm{~h}$, and it was due to the concentration gradient of phosphorus solution decreased gradually. In terms of HRT $=1 \mathrm{~h}$, the TP concentration in the effluent was about $1.35 \mathrm{mg} / \mathrm{L}$, and the TP removal rate was $94.82 \%$ after $8 \mathrm{~h}$. As the HRT increased to $2 \mathrm{~h}$, the final TP concentration in the effluent decreased to $0.69 \mathrm{mg} / \mathrm{L}$, and the removal rate further increased to $97.34 \%$. Similar phenomena can be observed when HRT was set as $3 \mathrm{~h}$, where the stable TP concentration in the effluent is about $0.20 \mathrm{mg} / \mathrm{L}$, which is meeting the standard of III class surface water. As expected, the low HRT will lead to the insufficient time for phosphate contact and react with adsorption sites, as well as the released active ions; thus, suitable HRT should be considered in the application. Additionally, it can be found that the performance of PTNC was better than the phosphorus removal effect of the mixture of iron scrap and sand as previous report (88\%) (Erickson et al., 2012). Table 6 showed the comparison of the TP removal ability of PTNC with other ceramsite. It can be found that PTNC presented highest TP adsorption capacity besides the Slag ceramsite reported by Liu et al. (2021). But the non-sintered preparation of PTNC is a more economical way. Thus, the prepared PTNC is promising for TP control and waste recycling.

\section{CONCLUSION}

In this research, a novel non-sintered ceramsite (PTNC) was prepared with pyrite tailings, and the preparation process was optimized by combination of PBD and BBD based response surface methodology, which confirmed the optimized mass ratios of the ingredients was $84.5 \mathrm{~g}$ (pyrite tailings), $10 \mathrm{~g}$ (cement), $1 \mathrm{~g}$ (calcined lime), $1 \mathrm{~g}$ (Anhydrous gypsum), $3 \mathrm{~g}$ (dehydrated sludge), and $0.5 \mathrm{~g}$ (sodium bicarbonate). PTNC presented favorable properties such as high specific surface, low leaching toxicity, and excellent mechanical strength. And the investigation on the adsorption behavior through batch and dynamic experiments showed the favorable adsorption capacity of PTNC, whose calculated $\mathrm{q}_{\max }$ was about $7 \mathrm{mg} / \mathrm{g}$, and can offer stable removal ability continuously under different HRT. The analysis of the adsorption mechanism suggested the existing of both physical and chemical adsorption effect. The total results make contribution to the resource of pyrite tailings, which are also benefit to the development of novel effective and economic medium for BAFS in the advanced treatment of wastewater.

\section{DATA AVAILABILITY STATEMENT}

The original contributions presented in the study are included in the article/Supplementary Material, further inquiries can be directed to the corresponding authors.

\section{AUTHOR CONTRIBUTIONS}

All authors contributed to the study conception and design. Material preparation, data collection and analysis were performed by RC, JX and ZP. The first draft of the manuscript was written by RC and all authors commented on previous versions of the manuscript. All authors read and approved the final manuscript.

\section{FUNDING}

This work was financially supported by the Public Research Project of Zhejiang Province (LGF20E090001 and LGF19E090002), the Science and Technology Projects of Wenzhou City (ZG2020024), and the Service Project for Science \& Technology Innovation of Wenzhou Association for Science and Technology (kjfw36).

\section{ACKNOWLEDGMENTS}

The authors appreciate all the participants.

\section{SUPPLEMENTARY MATERIAL}

The Supplementary Material for this article can be found online at: https://www.frontiersin.org/articles/10.3389/fchem.2022.850171/ full\#supplementary-material 


\section{REFERENCES}

Bao, T., Chen, T., Tan, J., Wille, M.-L., Zhu, D., Chen, D., et al. (2016). Synthesis and Performance of Iron Oxide-Based Porous Ceramsite in a Biological Aerated Filter for the Simultaneous Removal of Nitrogen and Phosphorus from Domestic Wastewater. Sep. Purif. Technol. 167, 154-162. doi:10.1016/j. seppur.2016.05.011

Bao, T., Damtie, M. M., Yu, Z. M., Liu, Y., Jin, J., Wu, K., et al. (2019). Green Synthesis of $\mathrm{Fe}_{3} \mathrm{O}_{4} @$ Carbon Filter Media for Simultaneous Phosphate Recovery and Nitrogen Removal from Domestic Wastewater in Biological Aerated Filters. ACS Sustain. Chem. Eng. 7 (19), 16698-16709. doi:10.1021/acssuschemeng. $9 \mathrm{~b} 04119$

Bashar, R., Gungor, K., Karthikeyan, K. G., and Barak, P. (2018). Cost Effectiveness of Phosphorus Removal Processes in Municipal Wastewater Treatment. Chemosphere 197, 280-290. doi:10.1016/j.chemosphere.2017.12.169

Bulut, G., Yenial, Ü., Emiroğlu, E., and Sirkeci, A. A. (2014). Arsenic Removal from Aqueous Solution Using Pyrite. J. Clean. Prod. 84, 526-532. doi:10.1016/j. jclepro.2013.08.018

Carvalho, P. C. S., Neiva, A. M. R., Silva, M. M. V. G., and Antunes, I. M. H. R. (2014). Metal and Metalloid Leaching from Tailings into Streamwater and Sediments in the Old Ag-Pb-Zn Terramonte Mine, Northern Portugal. Environ. Earth Sci. 71 (5), 2029-2041. doi:10.1007/s12665-013-2605-7

Chandra, A. P., and Gerson, A. R. (2010). The Mechanisms of Pyrite Oxidation and Leaching: a Fundamental Perspective. Surf. Sci. Rep. 65 (9), 293-315. doi:10. 1016/j.surfrep.2010.08.003

Chen, R., Liu, C., Johnson, N. W., Zhang, L., Mahendra, S., Liu, Y., et al. (2019a). Removal of 1,4-dioxane by Titanium Silicalite-1: Separation Mechanisms and Bioregeneration of Sorption Sites. Chem. Eng. J. 371, 193-202. doi:10.1016/j.cej. 2019.03.285

Chen, S., Chen, Y., Pei, H., and Hou, Q. (2019b). Biofilm Development Dynamics and Pollutant Removal Performance of Ceramsite Made from Drinking-water Treatment Sludge. Water Environ. Res. 91 (7), 616-627. doi:10.1002/wer.1089

Cheng, G., Li, Q., Su, Z., Sheng, S., and Fu, J. (2018). Preparation, Optimization, and Application of Sustainable Ceramsite Substrate from Coal Fly Ash/ Waterworks Sludge/oyster Shell for Phosphorus Immobilization in Constructed Wetlands. J. Clean. Prod. 175, 572-581. doi:10.1016/j.jclepro. 2017.12.102

Chero-Osorio, S., Chavez, D. M., Vega, A., Morales, A., Gamarra, C., and Rodriguez-Reyes, J. C. F. (2021). Reutilization of Pyrite-Rich Alkaline Leaching Tailings as Sorbent Must Consider the Interplay of Sorption and Desorption. Minerals Eng. 170, 107019. doi:10.1016/j.mineng.2021.107019

Chu, S. Y., Xiao, J. B., Tian, G. M., and Wong, M. H. (2014). Preparation and Characterization of Activated Carbon from Aquatic Macrophyte Debris and its Ability to Adsorb Anthraquinone Dyes. J. Ind. Eng. Chem. 20 (5), 3461-3466. doi:10.1016/j.jiec.2013.12.035

Dong, Y., Lin, H., and Zhang, X. (2020b). Simultaneous Ammonia Nitrogen and Phosphorus Removal from Micro-polluted Water by Biological Aerated Filters with Different media. Water Air Soil Poll. 231 (5), 1-15. doi:10.1007/s11270020-04616-9

Dong, Y., Zeng, W., Lin, H., and He, Y. (2020a). Preparation of a Novel WaterSoluble Organosilane Coating and its Performance for Inhibition of Pyrite Oxidation to Control Acid Mine Drainage at the Source. Appl. Surf. Sci. 531, 147328. doi:10.1016/j.apsusc.2020.147328

Erickson, A. J., Gulliver, J. S., and Weiss, P. T. (2012). Capturing Phosphates with Iron Enhanced Sand Filtration. Water Res. 46 (9), 3032-3042. doi:10.1016/j. watres.2012.03.009

Garcia, C., Ballester, A., Gonzalez, F., and Blázquez, M. L. (2005). Pyrite Behaviour in a Tailings Pond. Hydrometallurgy 76 (1-2), 25-36. doi:10.1016/j.hydromet. 2004.07.010

Ge, Z., Wei, D., Zhang, J., Hu, J., Liu, Z., and Li, R. (2019). Natural Pyrite to Enhance Simultaneous Long-Term Nitrogen and Phosphorus Removal in Constructed Wetland: Three Years of Pilot Study. Water Res. 148, 153-161. doi:10.1016/j.watres.2018.10.037

Guo, Z., Feng, Q., Wang, W., Huang, Y., Deng, J., and Xu, Z. (2016). Study on Flotation Tailings of Kaolinite-type Pyrite when Used as Cement Admixture and concrete Admixture. Proced. Environ. Sci. 31, 644-652. doi:10.1016/j. proenv.2016.02.118
Han, W., Yue, Q., Wu, S., Zhao, Y., Gao, B., Li, Q., et al. (2013). Application and Advantages of Novel clay Ceramic Particles (CCPs) in an Up-Flow Anaerobic Bio-Filter (UAF) for Wastewater Treatment. Bioresour. Technol. 137, 171-178. doi:10.1016/j.biortech.2013.03.124

He, B., and Wang, G. (2019). Is Ceramsite the Last Straw for Sewage Sludge Disposal: a Review of Sewage Sludge Disposal by Producing Ceramsite in China. Water Sci. Technol. 80 (1), 1-10. doi:10.2166/wst.2019.223

Heikkinen, P. M., and Räisänen, M. L. (2009). Trace Metal and as Solid-phase Speciation in Sulphide Mine Tailings - Indicators of Spatial Distribution of Sulphide Oxidation in Active Tailings Impoundments. Appl. Geochem. 24 (7), 1224-1237. doi:10.1016/j.apgeochem.2009.03.007

Jiang, C., Jia, L., Zhang, B., He, Y., and Kirumba, G. (2014). Comparison of Quartz Sand, Anthracite, Shale and Biological Ceramsite for Adsorptive Removal of Phosphorus from Aqueous Solution. J. Environ. Sci. 26 (2), 466-477. doi:10. 1016/s1001-0742(13)60410-6

Khale, D., and Chaudhary, R. (2007). Mechanism of Geopolymerization and Factors Influencing its Development: a Review. J. Mater. Sci. 42 (3), 729-746. doi:10.1007/s10853-006-0401-4

Li, L., Hu, C., Dai, X., Jin, W., Hu, C., and Ma, F. (2015). The Performance of a Biological Aerated Filter Loaded With a Novel Non-Sintered Fly-Ash Ceramsite as Pretreatment for Dual Membrane Processes. Environ Technol. 36 (16), 2024-2034. doi:10.1080/09593330.2015.1019930

Liu, X., Yang, S., Liu, S., and Yang, Y. (2021). Performance and Mechanism of Phosphorus Removal by Slag Ceramsite Filler. Process Saf. Environ. Prot. 148, 858-866. doi:10.1016/j.psep.2021.02.016

Malmström, M. E., Gleisner, M., and Herbert, R. B. (2006). Element Discharge from Pyritic Mine Tailings at Limited Oxygen Availability in Column Experiments. Appl. Geochem. 21 (1), 184-202.

Mi, H., Yi, L., Wu, Q., Xia, J., and Zhang, B. (2021). Preparation of High-Strength Ceramsite from Red Mud, Fly Ash, and Bentonite. Ceramics Int. 47 (13), 18218-18229. doi:10.1016/j.ceramint.2021.03.141

Nie, J., Wang, Q., Gao, S., Poon, C. S., Zhou, Y., and Li, J.-s. (2021). Novel Recycling of Incinerated Sewage Sludge Ash (ISSA) and Waste Bentonite as Ceramsite for Pb-Containing Wastewater Treatment: Performance and Mechanism. J. Environ. Manage. 288, 112382. doi:10.1016/j.jenvman.2021.112382

Oluwasola, E. A., Hainin, M. R., and Aziz, M. M. A. (2015). Evaluation of Asphalt Mixtures Incorporating Electric Arc Furnace Steel Slag and Copper Mine Tailings for Road Construction. Transp. Geotech. 2, 47-55. doi:10.1016/j.trgeo.2014.09.004

Ouyang, Y., Liu, Y., Zhu, R., Ge, F., Xu, T., Luo, Z., et al. (2015). Pyrite Oxidation Inhibition by Organosilane Coatings for Acid Mine Drainage Control. Minerals Eng. 72, 57-64. doi:10.1016/j.mineng.2014.12.020

Park, I., Tabelin, C. B., Jeon, S., Li, X., Seno, K., Ito, M., et al. (2019). A Review of Recent Strategies for Acid Mine Drainage Prevention and Mine Tailings Recycling. Chemosphere 219, 588-606. doi:10.1016/j.chemosphere.2018.11.053

Qiu, L., Zhang, S., Wang, G., and Du, M. a. (2010). Performances and Nitrification Properties of Biological Aerated Filters with Zeolite, Ceramic Particle and Carbonate media. Bioresour. Technol. 101 (19), 7245-7251. doi:10.1016/j. biortech.2010.04.034

Qiu, L., Zheng, P., Zhang, M., Yu, X., and Abbas, G. (2015). Phosphorus Removal Using Ferric-Calcium Complex as Precipitant: Parameters Optimization and PhosphorusRecycling Potential. Chem. Eng. J. 268, 230-235. doi:10.1016/j.cej.2014.12.107

Sahoo, P. K., Tripathy, S., Panigrahi, M. K., and Equeenuddin, M. K. (2013). Inhibition of Acid Mine Drainage from a Pyrite-Rich Mining Waste Using Industrial By-Products: Role of Neo-Formed Phases. Water Air Soil Poll 224 (11), 1-11. doi:10.1007/s11270-013-1757-0

Schindler, D. W., Carpenter, S. R., Chapra, S. C., Hecky, R. E., and Orihel, D. M. (2016). Reducing Phosphorus to Curb lake Eutrophication Is a success. Environ. Sci. Technol. 50 (17), 8923-8929. doi:10.1021/acs.est.6b02204

Shao, Q., Lu, M., Zhou, J., Zhu, Z., and Song, Y. (2019). Preparation of Nonsintered Fly Ash Filter (NSFF) for Ammonia Nitrogen Adsorption. Environ. Technol. 40 (15), 1988-1999. doi:10.1080/09593330.2018.1435733

Shao, Q., Zhang, Y., Liu, Z., Long, L., Liu, Z., Chen, Y., et al. (2022). Phosphorus and Nitrogen Recovery from Wastewater by Ceramsite: Adsorption Mechanism, Plant Cultivation and Sustainability Analysis. Sci. Total Environ. 805, 150288. doi:10.1016/j.scitotenv.2021.150288

Wang, H., Xu, J., Liu, Y., and Sheng, L. (2021). Preparation of Ceramsite from Municipal Sludge and its Application in Water Treatment: A Review. J. Environ. Manage. 287, 112374. doi:10.1016/j.jenvman.2021.112374 
Wang, S., and Mulligan, C. N. (2009). Enhanced Mobilization of Arsenic and Heavy Metals from Mine Tailings by Humic Acid. Chemosphere 74 (2), 274-279. doi:10.1016/j.chemosphere.2008.09.040

Wang, Y., Kim, J., and Song, J. (2014). Optimization for Manufacturing a Brake Booster Valve Body. Mater Design (1980-2015) 56, 313-317. doi:10.1016/j. matdes.2013.11.038

Wen, J., Han, X., Lin, H., Zheng, Y., and Chu, W. (2010). A Critical Study on the Adsorption of Heterocyclic Sulfur and Nitrogen Compounds by Activated Carbon: Equilibrium, Kinetics and Thermodynamics. Chem. Eng. J. 164 (1), 29-36. doi:10.1016/j.cej.2010.07.068

Xu, N., Christodoulatos, C., and Braida, W. (2006). Adsorption of Molybdate and Tetrathiomolybdate onto Pyrite and Goethite: Effect of $\mathrm{pH}$ and Competitive Anions. Chemosphere 62 (10), 1726-1735. doi:10.1016/j.chemosphere.2005.06.025

Yang, K., Yue, Q., Han, W., Kong, J., Gao, B., Zhao, P., et al. (2015). Effect of Novel Sludge and Coal Cinder Ceramic media in Combined Anaerobic-Aerobic BioFilter for Tetracycline Wastewater Treatment at Low Temperature. Chem. Eng. J. 277, 130-139. doi:10.1016/j.cej.2015.04.114

Yang, Y., Chen, T., Sumona, M., Gupta, B. S., Sun, Y., Hu, Z., et al. (2017). Utilization of Iron Sulfides for Wastewater Treatment: a Critical Review. Rev. Environ. Sci. Biotechnol. 16 (2), 289-308. doi:10.1007/s11157-0179432-3

Yue, Q., Han, S., Yue, M., Gao, B., Li, Q., Yu, H., et al. (2009). The Performance of Biological Anaerobic Filters Packed with Sludge-Fly Ash Ceramic Particles (SFCP) and Commercial Ceramic Particles (CCP) during the Restart Period: Effect of the C/N Ratios and Filter media. Bioresour. Technol. 100 (21), 5016-5020. doi:10.1016/j.biortech.2009.05.033
Zeng, Q., Chang, S., Wang, M., Li, M., Deng, Q., Xiong, Z., et al. (2021). Highlyactive, Metal-free, Carbon-Based ORR Cathode for Efficient Organics Removal and Electricity Generation in a PFC System. Chin. Chem. Lett. 32 (7), 2212-2216. doi:10.1016/j.cclet.2020.12.062

Zhang, Q., Chen, X., Wu, H., Luo, W., Liu, X., Feng, L., et al. (2019). Comparison of clay Ceramsite and Biodegradable Polymers as Carriers in Pack-Bed Biofilm Reactor for Nitrate Removal. Ijerph 16 (21), 4184-4198. doi:10.3390/ ijerph16214184

Conflict of Interest: The authors declare that the research was conducted in the absence of any commercial or financial relationships that could be construed as a potential conflict of interest.

Publisher's Note: All claims expressed in this article are solely those of the authors and do not necessarily represent those of their affiliated organizations, or those of the publisher, the editors and the reviewers. Any product that may be evaluated in this article, or claim that may be made by its manufacturer, is not guaranteed or endorsed by the publisher.

Copyright (c) 2022 Chen, Pan, Chu, Xiao, Weng, Ouyang, Yang, Wu and Huang This is an open-access article distributed under the terms of the Creative Commons Attribution License (CC BY). The use, distribution or reproduction in other forums is permitted, provided the original author(s) and the copyright owner(s) are credited and that the original publication in this journal is cited, in accordance with accepted academic practice. No use, distribution or reproduction is permitted which does not comply with these terms. 